\title{
Urbanización turística y ocupación del suelo en la península de Hicacos (Varadero, Cuba). Comportamientos diferenciados entre los espacios de uso público y privado
}

Ricardo Remond-Roa. Universidad de La Habana, La Habana, Cuba. Jesús M. González-Pérez. Universitat de les Illes Balears, Palma de Mallorca, España. Enrique Navarro-Jurado. Universidad de Málaga, Málaga, España.

RESUMEN | En la península de Hicacos se localiza Varadero, el principal polo turístico de Cuba y uno de los más antiguos e importantes del Caribe. El desarrollo hotelero del enclave, la especificidad del sistema cubano, así como una larga trayectoria en ordenación territorial, introducen una serie de particularidades respecto a otros destinos similares de sol y playa. Entre estos destacan los relativos a la ocupación y los usos del suelo. Los análisis y las conclusiones difieren según se trate de parcelas hoteleras o zona costera de uso público, por un lado, y el año de urbanización del territorio y la construcción del hotel, por otro. En este sentido, la aprobación de la Ley de Gestión de la Zona Costera de 1997 representa un hito de especial significación. Para estudiar estos procesos se emplearon herramientas de representación y análisis espacial presente en los Sistemas de Información Geográfica e imágenes de satélite de muy alta resolución espacial.

PALABRAS CLAVE | urbanización, ordenamiento territorial, indicadores ambientales.

ABSTRACT | Varadero is located in the Hicacos peninsula, the main tourist area in Cuba and one of the oldest and most important tourist areas in the Caribbean. Hotel development in the settlement, the specificity of the Cuban system, as well as an extensive experience in land-use planning, constitute a number of special features when compared to other similar of sun and sand destinations. Among these features, those related to land use and occupation are the most remarkable ones. The analysis and conclusions differ if we refer to hotel plots or coastal areas for public use, on one side, and the year of land urbanization and construction of the hotel, on the other side. In this regard, the approval of the Ley de Gestion de la Zona Costera [Law of Management of the Coastal Area] from 1997 represents a landmark of special importance. To study these processes, representation and spatial analysis tools present in Geographic Information Systems, as well as satellite images of very high spatial resolution were used.

KEYWORDs | urbanization, spatial planning, environmental indicators.

Recibido el 25 de noviembre de 2013, aprobado el 14 de julio de 2014

E-mail: Ricardo Remond, remond@geo.uh.cu | Jesús González, jesus.gonzalez@uib.es | Enrique Navarro, enavarro@uma.es 


\section{Introducción $^{1}$}

El turismo es un fenómeno global (Cazes, 1994; Violier, 2000) a través del que se conectan lugares, personas, economías y culturas y que, de forma inherente, se resuelve como actividad local, acentuando el carácter específico del lugar. En el inicio del siglo XXI, la actividad turística se había convertido en el sector económico más importante de muchos países y regiones y, a escala local, eso hizo del turismo el factor clave en la configuración de su espacio (Antón, 1998).

Hoy en día, y por regla general, el capital busca nuevas formas de inversión y ha encontrado en el turismo y los sectores afines un ámbito que permite obtener beneficios a corto plazo y que cuenta con buena imagen al "crear desarrollo", como dicen algunos eslóganes simplistas (Navarro-Jurado, Thiel-Ellul \& Romero-Padilla, 2015). Las transformaciones en la ocupación del suelo constituyen uno de los aspectos clave para entender la expansión de las actividades turísticas, sus impactos en el territorio y, en general, la construcción espacial. De esto deriva el interés científico por analizar la ocupación del suelo para uso turístico y los factores que intervienen en este proceso. Estos factores son principalmente la demanda turística, las presiones económicas sobre el territorio y el dilema que plantea extender la urbanización como medio para aumentar el número de visitantes, y conservar el territorio, en gran medida como estrategia para favorecer la atractibilidad de ese mismo territorio en proceso de explotación.

En Cuba, después de la caída del campo socialista, se comenzó a considerar el turismo como una alternativa importante para la recuperación de la economía. Para llevar a cabo este proyecto fue necesario impulsar la construcción de nuevas capacidades hoteleras e infraestructura turística (Salinas \& Mundet, 2000). Según datos de la Caribbean Tourism Organization, la llegada de turistas al Caribe creció en un 7,34\% entre 2000 y 2004. En Cuba, en ese mismo periodo, el número de turistas aumentó en un 15,47\%. Las consecuencias sobre el medioambiente, el territorio y la sociedad son importantes, pero no menos ambiciosos deben de ser los retos del ordenamiento territorial. En este proceso expansionista, el urbanismo y la planificación del territorio desempeńan un papel fundamental. Las particularidades del sistema cubano en cuanto a la propiedad pública del suelo y de los medios de producción deben ser tenidas en cuenta ante posibles comparaciones con otros países de la región.

En Cuba, el organismo rector de la planificación es el Instituto de Planificación Física (IPF), con sus departamentos provinciales (DPPF) y municipales. La lectura del planeamiento es poliédrica y las interpretaciones sobre sus resultados

$1 \longdiv { \text { La investigación que da lugar a este trabajo se financia con los siguientes proyectos de } }$ investigación: "Turismo y transformación de espacios urbanos. Análisis comparado y transferencia de conocimientos para diferentes ciudades de Cuba y la República Dominicana”, financiado por el Govern de les Illes Balears y la Oficina de Cooperació al Desenvolupament i Solidaritat (ocDs) de la Universitat de les Illes Balears (UіB) y "Geografías de la crisis: Análisis de los territorios urbano-turísticos de las Islas Baleares, Costa del Sol y principales destinos turísticos del Caribe y Centroamérica" (cso2012-30840) del Plan Nacional de I+D+I del Ministerio de Economía y Competitividad. Junto con agradecer tales aportes, nuestro reconocimiento a la ayuda y colaboración prestada por Daylis Rodríguez Capote, Jurguet Urra Medina y Eduardo Salinas Chávez, de la Universidad de La Habana. 
son complejas. Por un lado, hay ciertas evidencias de que sirve para canalizar inversiones turístico-residenciales; por ejemplo, en algunos casos los planes han sido más expansionistas de lo que la realidad económica permite (González et al., 2014). Por otro, la aplicación de la Ley de Gestión de la Zona Costera de 1997 ha servido para corregir errores del pasado y proteger territorio. En la península de Hicacos se ha aprobado un total de cuatro planes urbanos y territoriales, además de estar uno en proceso de aprobación. Los dos últimos planes de ordenamiento son de 1996 y 2001. Entre las principales aportaciones relativas a la ocupación del suelo destacan las medidas que evitan la urbanización continua, delimitando para esto zonas verdes en la península. No obstante, a escala de las parcelas hoteleras, solo tienen en cuenta las áreas edificadas, sin tomar en consideración las restantes formas de ocupación del suelo (áreas verdes, piscinas, zonas pavimentadas, etcétera) (Arias, 2005).

El polo turístico de Varadero tiene un alto grado de consolidación urbana, ha entrado en una etapa de madurez como destino turístico y hay indicadores que apuntan a que, a corto o medio plazo, entrará en una fase de estancamiento (González et al., 2014). En este contexto, el análisis y diagnóstico de la ocupación del suelo es fundamental para la detección de las debilidades y la propuesta de medidas correctoras. El objetivo principal de este trabajo es cartografiar la ocupación y los usos del suelo de la península de Hicacos, analizando, por un lado, las diferencias entre las parcelas hoteleras de uso privado y las zonas costeras de uso público; y, por otro, los contrates espaciales en la artificialización y sellado de suelo en función del período de urbanización del territorio y construcción de la infraestructura turística. Con estos planteamientos, la hipótesis del trabajo es la existencia de una diferente ocupación del suelo según se trate de parcelas hoteleras o zonas costeras, así como una diferente protección territorial y respeto por el dominio público en las actuaciones ejecutadas en la última década, que coinciden con los hoteles situados al final de la península. La aplicación de la Ley de Gestión de la Zona Costera de 1997 (Decreto-Ley N. ${ }^{\circ}$ 212) pudo haber sido decisiva en este aspecto, por cuanto identifica los límites de la zona costera y regula las actividades permitidas en la misma. En definitiva, este trabajo aporta datos inéditos sobre ocupación del suelo y tiene un claro componente aplicado, fundamentado en el diseño y aplicación de un Sistema de Información Geográfico (SIG) y el análisis de los datos e indicadores resultantes.

\section{Estado de la cuestión}

En la literatura científica hay trabajos sobre el modelo de crecimiento urbano-turístico en las islas caribeñas (Clarke, 1974; Weaver, 1993), pero son escasos los estudios sobre los modelos de ocupación y usos del suelo en los enclaves turísticos tipo resort. Una de las excepciones es el artículo de Weaver (1993) sobre los modelos de desarrollo urbano y turístico en las pequeñas islas del Caribe, donde construye un patrón de crecimiento evolutivo de círculos concéntricos alrededor del puerto de cruceros (entrada de turistas). La investigación pone de manifiesto que la excepción a este patrón son "the resort strips along the coast" (Weaver, 1993, p. 140). En estos espacios tipo flechas, como Varadero, localizados en Barbados, Antigua o Montserrat, el patrón dependerá de la cercanía al mar, con una primera línea de playa densamente 
poblada por hoteles, mientras que hacia el interior se ubican los condominios, apartamentos y pequeńos hoteles para turistas residenciales y elites locales.

En general, ni la geografía del turismo, centrada en la descripción de estudios de casos sin un enfoque integrador (Shaw \& Williams, 1994; Chang y \& Huang, 2004), ni la geografía urbana, centrada en otras funciones urbanas -vivienda, comercio, etcétera- (Aliagaoglu \& Ugur, 2008) han tratado en profundidad la ocupación y los usos del suelo en enclaves turísticos tipo resort aislado, como son Cancún, la Riviera Maya, Bávaro, Cayo Largo o Varadero.

No obstante, es más prolífica la literatura científica que estudia las distribuciones territoriales de los hoteles, fundamentalmente a escala urbana, y elabora modelos o patrones de implantación territorial (Ritter, 1989; Ashworth, 1989; Egan \& Nield, 2000; Shoval, 2006). El estudio pionero fue el planteamiento teórico de Yokeno (1968), al que se unen otros trabajos en distintas ciudades: Tel Aviv (Arbel \& Pizam, 1977), Toronto (Wall, Dudycha \& Hutchinson, 1985), Christchurch (Pearce, 1987), Europa occidental (Ashworth, 1989), Londres y otras ciudades del Reino Unido (Page \& Sinclair, 1989; Egan \& Nield, 2000), Nurnberg (Ritter, 1989), Viena (Hofmayer, 1986), Kansas (De Bres, 1994), Yogyekarta (Timothy \& Wall, 1995), Kuala Lumpur (Oppermann, Din \& Amri, 1996), Estambul (Dokmeci \& Balta, 1999; Kerimoglu \& Ciraci, 2006), Xiamen (Begin, 2000), Jerusalén (Shoval \& Cohen-Hattab 2001; Shoval, 2006) y Madrid (Urtasun \& Gutiérrez, 2006).

Según Ashworth y Tunbridge (1990), la distribución de los alojamientos se produce en función de cinco variables: accesibilidad, precios del suelo, servicios medioambientales, inercia histórica y planificación urbana. Cuando el turismo se implanta en un territorio pueden darse dos situaciones de partida (López \& Vera, 2001): a) que el turismo utilice un espacio en el que ya existe una estructura territorial con usos ya consolidados, un viario definido y una economía y sociedad tradicionales; b) que llegue a un espacio "virgen" sin apenas desarrollo territorial y deba crearse ex novo el destino. En el primer caso, el turismo se incorpora en el funcionamiento de la sociedad local y en la economía sin generar cambios profundos en el modelo de implantación preexistente. Es el caso de las grandes ciudades como La Habana. En el segundo tipo, y como tendencia general, los usos del suelo se dedican casi exclusivamente a fines turísticos, ya sea en un "núcleo turístico en el entorno de la ciudad”, como Cancún, o en un resort aislado, como en Bávaro o Varadero. De esta manera, la actividad turística que se implanta tiende a sustituir la base productiva predominante antes del inicio de la misma y dominan las lógicas económicas y territoriales en régimen de "monocultivo".

En nuestro caso, el modelo turístico dominante en el Caribe se ha caracterizado por la inserción de establecimientos hoteleros -manejados principalmente por capitales externos o mixtos- implantados a modo de enclave segregado tipo resort, donde el destino es manejado por grandes empresas transnacionales. Algunos autores se han referido a este modelo como un tipo de gated communities, a modo de "búnker de playa y sol" (Blázquez, Cañada \& Murray, 2011), y han sido analizados aplicando lo que Harvey (2004) denomina "acumulación por desposesión". La aplicación de esta teoría en el turismo no es frecuente y explica la ampliación espacial del turismo hacia la semiperiferia del sistema capitalista, como es el Caribe, 
contribuyendo a la pérdida de recursos y a un mayor deterioro socioecológico (Blázquez et al., 2011). Las diferencias entre destinos dependerán de los instrumentos políticos que se aprueben (leyes, planes...) y los objetivos que contemplen (integradores o parciales; conservacionistas o explotadores).

Como este modelo turístico se basa en el uso del frente litoral, la playa es el espacio más demandado, codiciado y conflictivo. Esto explica que las leyes que se aplican en la franja costera y la protección ambiental de las costas siempre sean temas controvertidos. La polarización de posturas y los múltiples intereses generados son habituales en todos los países, sobre todo en aquellos de uso intensivo del litoral por el turismo. En el Caribe, muchos países han desarrollado leyes, planes o programas de gestión costera. Son los casos de México, Costa Rica, Panamá, República Dominicana o Puerto Rico (Barragán, 2010). Y algunos de estos avanzan hacia una gobernanza costera más integral, incorporando el concepto de Gestión Integral de la Zona Costera.

En este sentido, un tema de análisis importante es el de las complejas relaciones entre el ordenamiento territorial del borde costero y el acceso real de la comunidad local a ese primer frente marítimo. Respecto a otros países del Caribe, Cuba destaca por tener unas leyes y planes del litoral más proteccionistas, lo que incluye una teórica utilización libre, pública y gratuita de las playas. Sin embargo, en ocasiones, los hoteles mantienen un estricto control sobre el acceso y las actividades que en ellas se desarrollan. Aun así, la situación es más grave en otros países de la región. Por ejemplo, en la República Dominicana se produce una privatización del uso de los arenales, hasta el punto de ser gestionados directamente por la empresa hotelera (desde el control del acceso a la playa misma hasta la administración y explotación de oferta complementaria). En este país, los bienes de dominio marítimo-terrestre pertenecen al Estado y, por lo tanto, todo ciudadano tiene derecho a su disfrute (art. 145, Ley N. ${ }^{\circ}$ 64-00 sobre Medio Ambiente y Recursos Naturales). Sin embargo, los residentes y las personas no alojadas en los hoteles no tienen acceso a la playa, no solo para el disfrute de la misma, sino también para la explotación de los recursos pesqueros, puesto que no pueden llegar con sus embarcaciones al mar. Únicamente se mantienen unas pequeńas servidumbres de paso y unos reducidos sectores de playa pública (González, 2012).

Según Prieto y Ruiz (2013), la compatibilidad entre el turismo y otros usos potenciales del borde costero no tiene por qué ser conflictiva. Ello dependerá del tratamiento como bien común otorgado a las costas, frente al riesgo de colapso por privatización, arbitrariedad y falta de enfoque científico. No obstante, en la práctica, los conflictos y las disputas espaciales son numerosos. La causa es que los operadores turísticos y las trasnacionales hoteleras buscan la proximidad al mar, lo que implica levantar edificios de diferentes dimensiones en primera línea de playa. Así, el uso y los límites de la franja costera para construir alojamientos, servicios e infraestructura se convierten en el tema clave de la política costera. Las diferencias por países son destacadas. Por ejemplo, Costa Rica dispone de una franja costera de 200 metros de ancho -a partir del promedio de la pleamar- con dos límites: en los primeros 50 metros, el uso es público (incluidos sistemas de manglar) y los otros 150 metros se denominan "zona de concesión", que se otorga para el desarrollo de 
actividades reguladas y controladas por la ley (Morales, Silva \& González, 2010). En Argentina, la Ley 4.739/1939 sobre Urbanización de Playas y Riberas y el Decreto Ley 8.912/1977 de Ordenamiento Territorial y Uso del Suelo limitan la edificación a 100 metros de la costa. En España, el nuevo giro neoliberal en el gobierno implicó el cambio de la ley y, desde mayo de 2013, está vigente la Ley de Protección y Uso Sostenible del Litoral, que deroga el deslinde marítimo-terrestre en los 100 metros para toda la costa y en muchos casos se reduce a 20 metros. Esto está suponiendo una mayor explotación del litoral, incluso favoreciendo algunos intereses particulares (Prieto \& Ruiz, 2013). En Cuba, la ley establece dos tipos de zonas: la costera y la de protección, que hay que delimitar según el tipo de costa. Más allá de la zona de protección, la edificación está permitida, salvo que sean construcciones de madera no permanentes (como los denominados "ranchones"). Por ejemplo, en las zonas de terrazas y acantilados, la zona de protección es de 20 metros y en la playa asciende a los 40 metros (Rey, Cruz, López, Whittle \& Kanepa, 2008).

En conclusión, el interés por el conocimiento de la ocupación y los usos del suelo en los enclaves turísticos adquiere relevancia porque traduce los objetivos políticos y los intereses de las trasnacionales, y mide el impacto territorial y el cumplimiento de las leyes. Estudios como el que se plantea en este artículo tienen un importante carácter aplicado, al proporcionar datos y cartografía fundamentales para el planeamiento y gestión territorial, y abren una interesante línea de investigación poco trabajada en la actualidad no solo en el Caribe, sino también en otros destinos de sol y playa.

\section{Metodología y fuentes}

El diseño, la representación y aplicación de un sig sobre ocupación y usos del suelo representan el apartado central del trabajo y la fuente principal de donde extraer los resultados para su análisis. La metodología diseñada es fácilmente extrapolable a otros territorios litorales y puede servir de base para diferentes investigaciones. Los principales materiales utilizados fueron los mapas topográficos a escala 1:2000, imagen de satélite GeoEjes-1 del año 2009 e información geográfica levantada durante el trabajo de campo. La metodología ha sido resumida en la Figura 1 a partir del desarrollo de dos variables: la elaboración de la base cartográfica y datos de interés (digitalización vectorial), y elaboración del mapa de uso y vegetación (procesamiento digital). El resultado esperado es la clasificación de hoteles según la ocupación del suelo (Figura 1). Por su parte, la periodización para la elaboración del SIG se resume en cinco etapas:

1. Generación del mapa de uso del suelo a partir del procesamiento digital de imágenes de satélite de muy alta resolución espacial.

2. Comprobación del mapa de uso del suelo.

3. Trazado de la zona costera y sus límites.

4. Análisis de la ocupación del suelo:

- en las parcelas hoteleras

- en la zona costera

5. Clasificación de los hoteles de acuerdo con la ocupación del suelo. 
FIGURA I | Esquema metodológico del sig

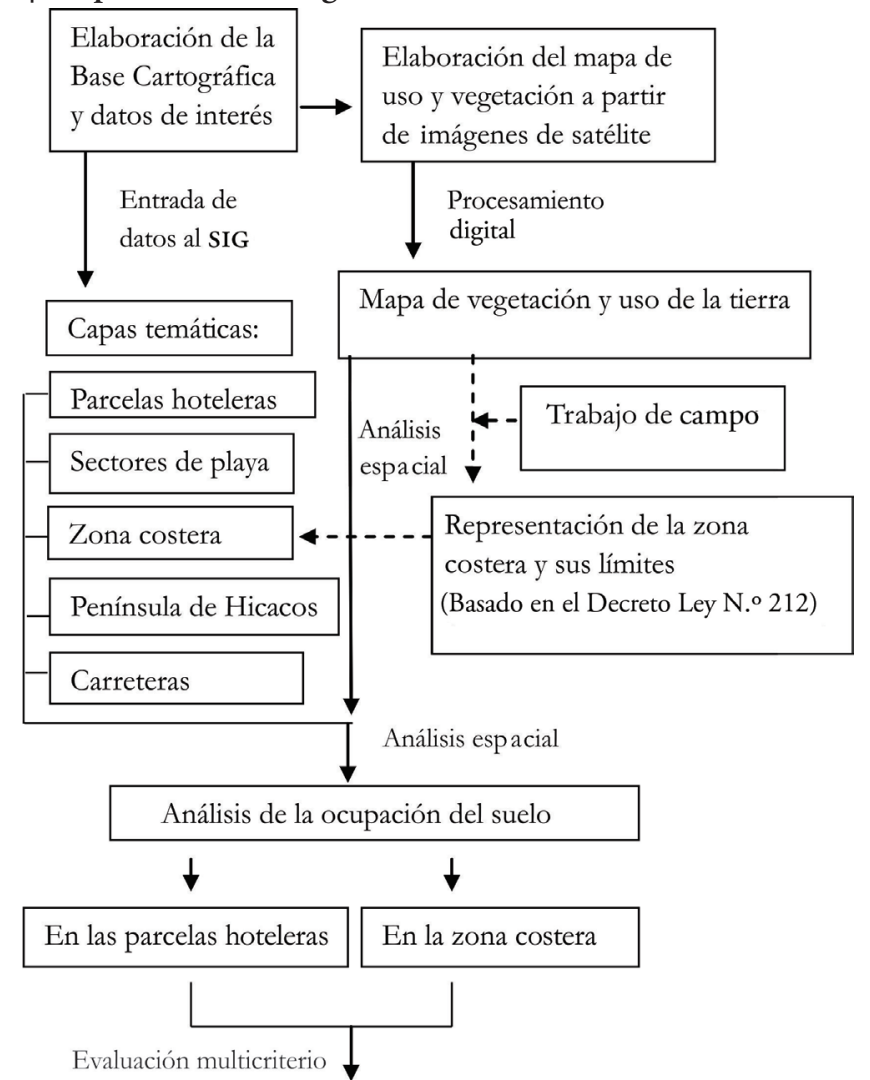

Clasificación de los hoteles de acuerdo a la ocupación del suelo

FUENTE ELABORACIÓN PROPIA

\section{Generación del mapa de uso del suelo}

Una de las primeras tareas de la investigación fue la elaboración del mapa de uso del suelo. Para esto se adquirió una imagen del satélite GeoEye-1 (2009) que cubre la superficie de la península. A partir de las técnicas del procesamiento digital de imágenes y las clasificaciones supervisadas se generaron las siguientes categorías de uso del suelo:

- Áreas verdes naturales: restos de vegetación natural y vegetación reforestada con plantas autóctonas.

- Áreas verdes artificiales: espacios de jardines en el interior de las parcelas hoteleras.

- Arenas: la franja de sol y arena de la zona costera y los espacios con arenas en el interior de los hoteles. 
- Áreas selladas: las áreas antropizadas donde se ha eliminado la vegetación con la finalidad de construir sobre ellas. Incluye las áreas edificadas, los ranchones, las piscinas, las canchas deportivas y las zonas pavimentadas.

Comprobación del mapa de uso del suelo

A partir de la información aportada en el trabajo de campo y la interpretación visual de las imágenes de satélite, se corrigieron los errores de la clasificación con el empleo de las herramientas de edición en los sig. Posteriormente, utilizando una máscara en el sig, se recortó el mapa de uso obtenido, de tal forma que solo quedó representado el interior de las parcelas hoteleras y la zona costera al norte de cada hotel.

\section{Trazado de la zona costera y sus límites}

De acuerdo con los criterios recogidos en el Decreto-Ley N.212, se siguieron las siguientes etapas para la representación de la zona costera:

- Identificación de los tipos de costa (arenosa de dunas, acantilados, terraza baja).

- Identificación del límite exterior de la duna.

- Análisis espacial en el sig.

- Edición cartográfica en el sig.

FIGURA 2 Ejemplo de delimitación de trazados de la zona costera y de la parcela hotelera y zona costera

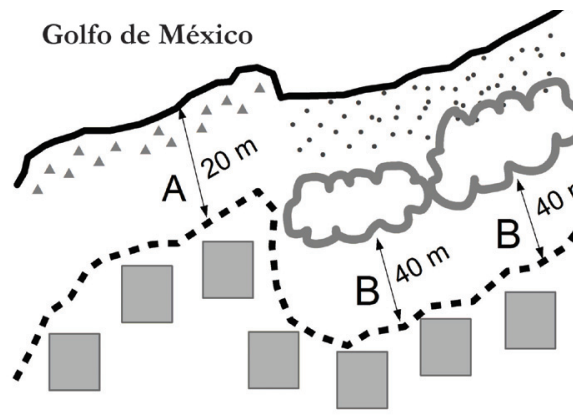

- - Límite interior de la zona costera

A $20 \mathrm{~m}$ de distancia del acantilado

B $40 \mathrm{~m}$ a partir de la franja de vegetaci consolidada más próxima al mar

- Línea de la costa

Franja de vegetación consolidada

Instalaciones hoteleras

Hotel Be Live Turquesa

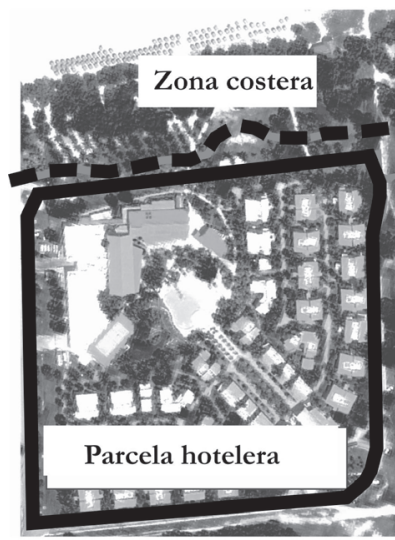

- Perímetro de la parcela hotelera

- Límite interior de la zona costera (según decreto Ley N.212)

Trazado de la zona costera

Trazados parcela hotelera y zona costera

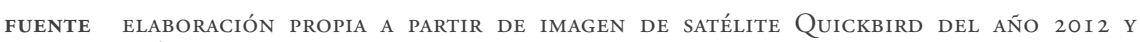
ANÁLISIS EN EL SIG 
Para cumplir con las tres primeras etapas se realizó trabajo de campo en el área de estudio, fundamentalmente en su costa norte, que es aquella con mayor implantación hotelera. Con el empleo de un Sistema de Posicionamiento Global (GPS) se cartografiaron los diferentes tipos de costas, el límite exterior de las dunas y la franja de vegetación más próxima a la terraza baja. Con el empleo de las herramientas de análisis en los SIG (principalmente las herramientas de superposición en el modelo vectorial y la generación de áreas de influencia), y teniendo en cuenta los criterios contenidos en la ley, se realizó la cartografía de la zona costera. La imagen izquierda de la Figura 2 representa una pequeña zona costera en el entorno del hotel Alegro Varadero, que sirve de ejemplo del tipo de delimitación que se ha realizado para toda la península (Figura 2).

\section{Análisis de la ocupación del suelo}

En esta cuarta fase se analizó la ocupación del suelo en el interior de cada parcela hotelera y en la zona costera situada delante de cada hotel. La imagen derecha de la Figura 2 representa las áreas delimitadas de zonas hotelera y costera en un pequeño sector de la costa de la península. Como en el anterior caso, esta es un ejemplo de la metodología adoptada, a gran escala, en la elaboración de la cartografía y la consecuente obtención de datos para toda la península de Hicacos (Figura 2).

- Análisis en las parcelas hoteleras. Se calculó la superficie ocupada por cada categoría de uso del suelo y qué porcentaje representaba dentro de la parcela hotelera. Con este procedimiento se identificaron aquellos hoteles con más áreas verdes naturales y aquellos otros con una mayor superficie de áreas selladas.

- Análisis en la zona costera. Se calculó la superficie ocupada por cada categoría de uso del suelo y qué porcentaje representaba dentro de la zona costera. Con este procedimiento se identificaron los hoteles que tienen áreas selladas en el interior de la zona costera.

\section{Clasificación de los hoteles de acuerdo con la ocupación del suelo}

En esta última etapa se clasificaron los hoteles de acuerdo con el estado de la ocupación del suelo en su interior y en la zona costera. Se les asignó un valor (en una escala entre 0 y 3 puntos), teniendo en cuenta los resultados del cálculo de los indicadores:

- Porcentaje de área sellada con relación al tamaño de la parcela hotelera.

1. (de $28-49,9 \%)$

2. (de $50-74,9 \%)$

3. (más del $75 \%$ )

- Porcentaje de áreas verdes con relación al tamaño de la parcela hotelera.

1. (más del $50 \%$ )

2. (de $25-49,5 \%)$

3. (de 4-24,9\%)

- Porcentaje de la zona costera ocupada por la parcela.

$0 . \quad$ (no tiene)

1. (de 1-24,9\%) 
2. (de $25-49,9 \%)$

3. (más de $50 \%$ )

- $\quad$ Porcentaje de la zona costera ocupada por áreas selladas

$0 . \quad$ (no tiene)

1. $(1-9,9 \%)$

2. $(10-19,9 \%)$

3. (más del 20\%)

En la selección de los intervalos de cada indicador se analizó el histograma de frecuencia de cada variable.

Por último, se sumaron los valores obtenidos por cada indicador en cada uno de los hoteles. Los resultados se almacenaron en una columna de la base de datos. La interpretación de esta columna permitió clasificar e identificar a los hoteles que tienen una ocupación del suelo menos agresiva con el territorio y más respetuosos con la normativa vigente en ordenación del litoral. Los valores más bajos significan que los hoteles a los cuales se les asignan tienen menos superficie sellada y más áreas verdes dentro de su parcela hotelera. Asimismo, esto indica que tienen menos o ningún área de su parcela dentro de la zona costera.

A partir del análisis del histograma de frecuencia y con el empleo del método cartográfico de los cuantiles, los hoteles se clasificaron en cuatro grupos según la ocupación del espacio en su interior y zona costera. En la medida en que la puntuación sea más baja (grupo 1), los hoteles hacen una mejor ocupación del suelo. Finalmente, para dar respuesta a la hipótesis de partida, se analizó la relación entre la puntuación alcanzada por cada hotel y el año de inauguración del mismo.

\section{Área de estudio. Delimitación de la zona costera y de la península turística de Hicacos}

La definición y delimitación de la zona costera poseen diferentes acepciones. La falta de precisión o acuerdo se extiende a la literatura científica. Autores como García (1987), Barragán (1994), Seco (2004) o, más recientemente, Zoido et al. (2013) intentan establecer los límites, inferior y superior, de la zona litoral. En este trabajo se tomará la acepción publicada en el artículo dos del capítulo uno del Decreto-Ley N. 212 Gestión de la Zona Costera. Según este, se define como zona costera "la franja marítimo-terrestre de ancho variable, donde se produce la interacción de la tierra, el mar y la atmósfera, mediante procesos naturales. En la misma se desarrollan formas exclusivas de ecosistemas frágiles y se manifiestan relaciones particulares económicas, sociales y culturales" (Consejo de Estado de la República de Cuba, 2000). Los límites de la denominada Zona Costera se establecen atendiendo a la estructura y configuración de los distintos tipos de costas. El límite interior (hacia tierra adentro) se establece por la existencia de playa, ausencia de la duna y costa baja de manglar. Cuando no existan los casos descritos en los incisos anteriores, el límite hacia tierra se extiende veinte metros a partir de donde hayan alcanzado las olas de los mayores temporales conocidos o cuando lo supere la línea de pleamar máxima equinoccial. El límite exterior (hacia el mar) es el borde de la plataforma 
insular del territorio, regularmente a profundidades entre cien y doscientos metros. A partir de la Zona Costera se establece la Zona de Protección. Según los casos, esta tendrá una anchura mínima de entre 20 y 30 metros medidos a partir del límite hacia tierra de la zona costera.

Los usos y la protección de la zona costera están regulados fundamentalmente por los artículos 15.1 y 16. Según estos, por un lado, la zona costera permanecerá preferentemente desocupada, autorizándose solamente el desarrollo o la ejecución de actividades o instalaciones que por su propia naturaleza no admiten otra ubicación (puertos, embarcaderos, astilleros, marinas, varaderos, termoeléctricas, parques submarinos, plataformas de perforación de petróleo, etcétera). Por otro, salvo excepciones, en la zona costera se prohíbe la instalación de nueva edificación, la extracción de áridos, el estacionamiento y la circulación de vehículos terrestres, la creación o ampliación de nuevas áreas residenciales o de alojamiento, la ampliación de las edificaciones existentes ocupando áreas de la zona costera y de protección, la circulación de vehículos acuáticos y motorizados en áreas donde haya sido prohibida o limitada por los organismos correspondientes; la disposición final de los desechos sólidos y líquidos provenientes de cualquier actividad, cuando no cumplan con las normas de vertimientos establecidas; la introducción de especies exóticas; y las actividades de equitación, circulación de animales de tiro y de vehículos de tracción animal, en las playas.

La península de Hicacos tiene una longitud de $23 \mathrm{~km}$ y un ancho promedio de un kilómetro. Está formada por una barra de arenas, manglares y acantilados. En la actualidad, más del $70 \%$ de la península está edificada o en proceso de edificación (Arias, 2011). Y de acuerdo con las delimitaciones establecidas por esta ley, la zona costera representa el $11,69 \%\left(1,78 \mathrm{~km}^{2}\right)$ de la superficie de la península de Hicacos. El largo e intenso desarrollo turístico es responsable de las principales dinámicas económicas, sociales, espaciales y ambientales de este territorio. La península está capitalizada por el polo turístico de Varadero que, situado a $140 \mathrm{~km}$ de La Habana, es el primer destino turístico de Cuba. Recibe cada año más de un millón de visitantes, lo que representa el $41 \%$ de los turistas que arriban a Cuba; sumaba 18.752 habitaciones en 2010 (el 35\% de las habitaciones del país) y contabilizaba el 42,9\% de las pernoctaciones totales (Ministerio de Turismo [MINTUR], 2011).

Varadero ha conocido tres fases de desarrollo urbanístico directamente relacionadas con tres impulsos turísticos principales. Este enclave se fundó en 1883 como un poblado para temporadas de baño, y a principios de 1900 recibió los primeros visitantes relacionados con la celebración de regatas. En esos años se convirtió en lugar de veraneo de ricos y famosos, como la familia DuPont, y se construyeron algunos alojamientos emblemáticos, como los hoteles Varadero (1915) y, más adelante, Internacional (1950). Esta fase tuvo un desarrollo turístico muy concentrado en el extremo oeste de la península y alrededor de lo que hoy conocemos como Varadero Histórico. En la segunda fase (1959-1990), tras el triunfo de la Revolución, se nacionalizaron las instalaciones turísticas y Varadero se volcó a la población cubana y a pequeños grupos de turistas procedentes de los países socialistas de Europa. Se estableció el libre acceso de todas las personas a la playa. En esta etapa no hubo apenas crecimiento turístico (solo cuatro hoteles) ni urbanístico, 
pero se sentaron las bases del crecimiento futuro con la redacción, en 1977, del Esquema de Desarrollo de Varadero 2000. Este plan zonificó el territorio en siete sectores turísticos, cada uno coincidente con una etapa de la urbanización y desarrollo turístico del enclave. Cuatro de estos sectores están situados en el denominado Viejo Varadero: sectores Oasis, Kawana, Varadero Histórico e Internacional; y tres en el Nuevo Varadero: Las Américas, Chapelín-Los Taínos y Punta Hicacos. La tercera etapa comenzó en la década de 1990 y en ella se consolida la estructura urbana actual y la tipología de destino turístico tal y como hoy lo conocemos, contribuyendo a hacer de Varadero un tipo de ciudad polarizada (González et al., 2014) (Figura 3). El impulso proporcionado por el Estado cubano al desarrollo del turismo internacional en los años 1990 produjo un crecimiento explosivo en la construcción de hoteles, en el arribo de visitantes y en los ingresos por turismo.

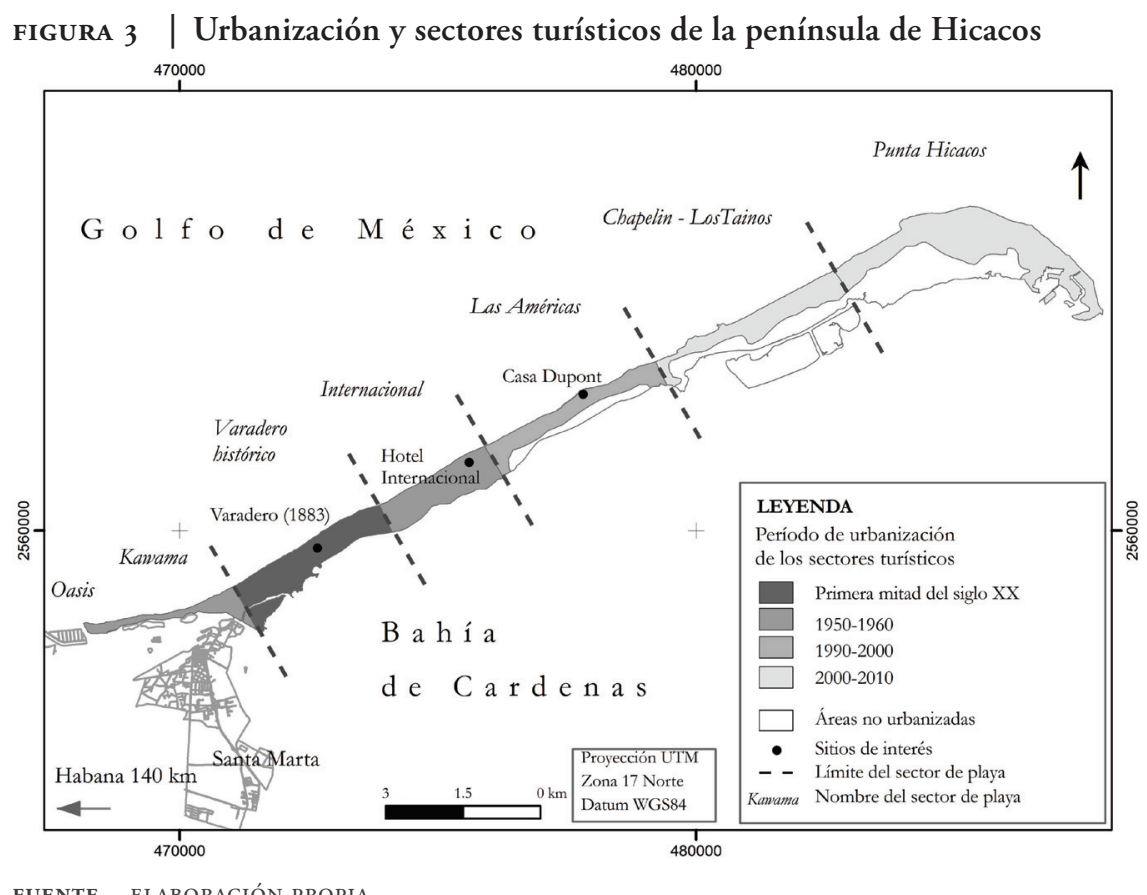

FUENTE ELABORACIÓN PROPIA

Una parte importante de estos desarrollos turísticos y urbanísticos está relacionada con una destacada actividad planificadora. Desde mediados de la década de 1970, Varadero ha aprobado tres planes urbanos y territoriales: Plan Director para el Desarrollo Integral de Varadero (1988), Plan Director Urbano (1996) y Plan de Ordenamiento Territorial y del Urbanismo del polo turístico de Varadero (2001). A estos hay que sumar el Plan General de Ordenamiento Territorial y del Urbanismo, ya redactado pero pendiente de aprobación definitiva. El sistema de planeamiento es complejo, bien organizado y jerarquizado. Sin embargo, la mayoría de los planes son, en primer lugar, más expansionistas de lo que la realidad económica permitía 
al momento de su entrada en vigencia. Algunos han actuado como instrumentos canalizadores de las inversiones, colocando mucho suelo en el mercado turístico. Segundo, estos planes centran sus esfuerzos en proteger determinadas áreas de alto valor natural, otorgando una valoración residual al suelo restante (González et al., 2014). En tercer lugar, se planifica el desarrollo de Varadero bajo la concepción de un territorio para uso fundamentalmente turístico y recreativo.

Por último, esta expansión turística tiene igualmente consecuencias de tipo ambiental, entre las que destacan la contaminación del agua en algunos sectores; la erosión costera y la desaparición de arena de la playa; y la degradación de hábitat y pérdida de la biodiversidad, con la desecación de la laguna y el deterioro de la salina en Punta Hicacos. Aunque hay que reconocer los éxitos de algunos planes en materia de protección del territorio y recuperación ambiental, la creciente artificialización del suelo es una de las mayores amenazas que está sufriendo la península, hasta el punto de que puede propiciar su decadencia como destino turístico. La expansión de la Marina de Varadero en este sector no está mejorando la calidad ambiental del enclave.

\section{Resultados y discusión}

\section{Ocupación del suelo por parcelas hoteleras}

En 2009, más de una cuarta parte de la península de Hicacos estaba ocupada por parcelas hoteleras. Estas suman una superficie de $4,10 \mathrm{~km}^{2}$, lo que representa el $26,96 \%$ de la península. En general, el área ocupada por parcelas en cada sector es proporcional a su tamaño, excepto en el caso de Varadero Histórico y, en menor medida, Kawana. Estas dos zonas son las de desarrollo turístico más antiguo. A pesar de ser el tercer sector en extensión, Varadero Histórico tiene la menor superficie ocupada por parcelas hoteleras. Como espacio urbano-turístico de origen fordista, tiene mezcla de usos y es el lugar donde se concentran las actividades no propiamente hoteleras (servicios, comercial y alguna de tipo residencial) complementarias a los resorts de toda la península. En el caso contrario, Punta Hicacos es, con diferencia, la que tiene más superficie ocupada $(38,70 \%)$, seguido de Chapelín-Los Taínos $(21,15 \%)$. Estos sectores no son los que tienen mayor número de hoteles, pero sí los que tienen complejos o resorts con mayor superficie. La mezcla de usos es casi inexistente y todos los servicios para el turista se concentran en el interior de las parcelas hoteleras. Situados en la punta más extrema de la península, coinciden con los desarrollos turísticos más recientes: 1990-2000 (Chapelín-Los Taínos) y 2000-2013 (Punta Hicacos). En resumen, los hoteles ocupan proporcionalmente menos suelo en los sectores más antiguos. Los desarrollos más recientes, aquellos construidos fundamentalmente desde 1990 y que mayoritariamente pertenecen a las grandes cadenas internacionales, ocupan mucho suelo debido a la importancia concedida a las áreas verdes y otro tipo de áreas selladas que complementan la función exclusivamente hotelera de la infraestructura. En consecuencia, los desarrollos turísticos más jóvenes "privatizan” el uso del suelo en mayor medida que los más antiguos (Tabla 1). 
TABLA I | Superficie de las parcelas hoteleras por sectores

\begin{tabular}{|l|c|c|c|}
\hline \multicolumn{1}{|c|}{ SECTORES } & $\begin{array}{c}\text { SUPERFICIE DEL } \\
\text { SECTOR }\left(\mathbf{K M}^{2}\right)\end{array}$ & $\begin{array}{c}\text { SUPERFICIE DE LAS } \\
\text { PARCELAS HOTELERAS } \\
\left(\mathbf{K M}^{2}\right)\end{array}$ & $\begin{array}{c}\text { \% DE LA SUPERFICIE } \\
\text { DEL SECTOR OCUPADA } \\
\text { POR PARCELAS }\end{array}$ \\
\hline Punta Hicacos & 5,45 & 1,58 & 38,70 \\
\hline Chapelín-Los Taínos & 3,82 & 0,86 & 21,15 \\
\hline Las Américas & 1,80 & 0,49 & 11,97 \\
\hline Internacional & 1,51 & 0,66 & 16,25 \\
\hline Kawama & 0,67 & 0,33 & 8,12 \\
\hline Varadero Histórico & 1,97 & 0,15 & 3,81 \\
\hline Península de Hicacos & 15,22 & 4,10 & 26,96 \\
\hline
\end{tabular}

FUENTE ELABORACIÓN PROPIA

La ocupación del suelo en el interior de las parcelas hoteleras

Si desplazamos el análisis al interior de las parcelas hoteleras, se observa que algo más de la mitad de la superficie está ocupado por áreas verdes $(52,60 \%)$, seguido de un alto porcentaje de otras áreas selladas (46,21\%) y un 1,19\% de arenas. En este análisis se excluyeron las parcelas de los hoteles El Patriarca y Laguna Dorada, debido a que en la fecha en que fue tomada la imagen de satélite (abril de 2009), estaban en construcción y, por lo tanto, no se pudo cartografiar con precisión la ocupación del suelo en su interior (Tabla 2).

TABLA 2 Ocupación del suelo en las parcelas hoteleras de la península de Hicacos

\begin{tabular}{|l|c|c|}
\hline \multicolumn{1}{|c|}{$\begin{array}{c}\text { CATEGORÍAS DE USOS } \\
\text { DEL SUELO }\end{array}$} & SUPERFICIE $\left(\mathbf{K M}^{2}\right)$ & $\begin{array}{c}\text { \% DEL ÁREA OCUPADA } \\
\text { EN LAS PARCELAS }\end{array}$ \\
\hline Áreas verdes & 2,01 & 52,60 \\
\hline Áreas selladas & 1,77 & 46,21 \\
\hline Arenas & 0,05 & 1,19 \\
\hline Área total de las parcelas & 3,83 & 100 \\
\hline
\end{tabular}

FUENTE ELABORACIÓN PROPIA

Este 52,60\% de áreas verdes manifiesta, en principio, valores positivos. Sin embargo, si este índice se estudia con mayor detalle, tal y como se desagrega en la Tabla 3, se observa que $1,97 \mathrm{~km}^{2}$ (de un total de $2,01 \mathrm{~km}^{2}$ ) son artificiales. El porcentaje de superficie ocupada por áreas verdes naturales y reforestadas es muy bajo (1,24\%). En cuanto a las áreas selladas, la mayor cantidad corresponde a las pavimentadas y ocupadas por edificaciones que, en algunos hoteles, llegan a representar más de la mitad de su superficie. En menor medida se encuentran las áreas ocupadas por piscinas, canchas deportivas y ranchones. Estos últimos representan solo el 0,45\% del área total de las parcelas, debido a que generalmente se localizan en las zonas costeras y de protección definida en el Decreto-Ley N. ${ }^{\circ} 212$; por lo tanto, incumpliendo esta normativa territorial (Tabla 3). 
TABLA 3 Ocupación del suelo en las parcelas hoteleras por categorías de uso

\begin{tabular}{|l|l|c|c|}
\hline \multicolumn{2}{|c|}{ CATEGORÍAS DE USO DEL SUELO } & SUPERFICIE $\left(\mathbf{K M}^{2}\right)$ & $\begin{array}{c}\text { \% DEL ÁREA OCUPADA } \\
\text { EN LAS PARCELAS }\end{array}$ \\
\hline \multirow{3}{*}{ Áreas verdes } & Naturales y reforestadas & 0,05 & 1,24 \\
\cline { 2 - 4 } & Verdes artificiales & 1,97 & 51,36 \\
\hline \multirow{2}{*}{ Arenas } & Áreas pavimentadas & 0,05 & 1,19 \\
\hline \multirow{3}{*}{ Áreas selladas } & Edificaciones & 0,89 & 23,21 \\
\cline { 2 - 4 } & Ranchones & 0,75 & 19,58 \\
\cline { 2 - 4 } & Piscinas & 0,02 & 0,45 \\
\cline { 2 - 4 } & Canchas deportivas & 0,06 & 1,54 \\
\hline
\end{tabular}

FUENTE ELABORACIÓN PROPIA

GRÁfICO I | Relación de hoteles según la superficie sellada: a) \% en relación con la parcela hotelera; b) según su superficie sellada $\left(\mathrm{en}^{\mathrm{k}}{ }^{2}\right)$
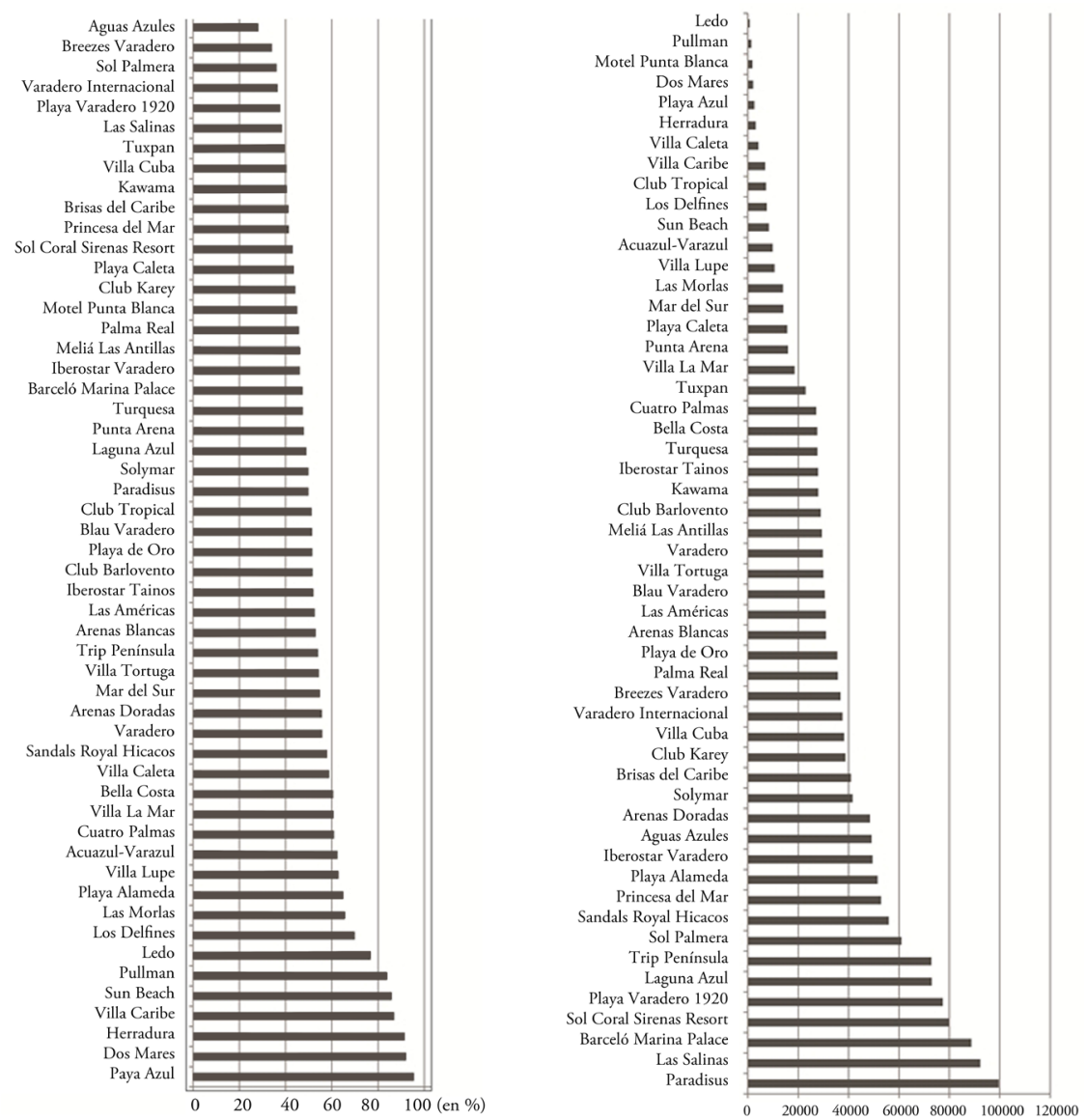
Si este análisis se detalla a la superficie sellada al nivel de cada uno de los hoteles del enclave, se observa cómo los complejos construidos en las dos etapas de mayor impulso turístico (décadas de 1950-1960 y desde 1990) son los que tienen un porcentaje más importante de áreas selladas. No obstante, es necesario matizar estos datos por cuanto, fundamentalmente en los casos más antiguos, la superficie total es pequeńa si se la compara con los resorts de construcción más reciente. En la actualidad, los nuevos complejos hoteleros ocupan parcelas muy extensas y, si bien pueden tener áreas selladas proporcionalmente poco importantes, sí alcanzan valores absolutos elevados. Son los casos de los hoteles Las Salinas, Paradisus, etcétera. Esto es un dato importante, porque demuestra la capacidad de transformación territorial y ambiental de los nuevos resorts. Así, estos no solo ocupan mucho suelo, sino que alteran el entorno ecológico donde se asientan (Gráfico 1).

\section{La ocupación del suelo en la zona costera}

La zona costera de la península de Hicacos tiene una superficie de $1,78 \mathrm{~km}^{2}$. La ocupación y el uso que los resorts hacen del territorio inmediatamente anterior a esta zona, e incluso de ella misma, es muy elevado. Por un lado, la primera línea de playa situada detrás del límite de la zona costera está ocupada en un 82,02\%. Es decir, las instalaciones hoteleras se extienden hacia los arenales hasta lo máximo permitido. Por otro, 46 de los 53 hoteles estudiados ocupan, en mayor o menor medida, el sector costero localizado frente a ellos. Esto es una muestra de la intensa presión territorial ejercida por esta tipología turística sobre el medio. En la zona costera frente a cada hotel predomina la franja de sol y arena, seguida de las áreas verdes y, en menor grado, las áreas selladas. En este último caso, se trata de hoteles construidos antes de la aprobación de la ley de 1997 y, en algunos casos, se ha constatado que se trata de violaciones de esta norma (Tabla 4).

TABLA 4 Ocupación del suelo en la zona costera

\begin{tabular}{|l|c|c|}
\hline $\begin{array}{c}\text { CATEGORÍAS DE USO } \\
\text { DEL SUELO }\end{array}$ & SUPERFICIE $\left(\mathbf{M}^{2}\right)$ & $\begin{array}{c}\text { \% DE LA ZONA COSTERA } \\
\text { OCUPADA }\end{array}$ \\
\hline Áreas verdes & $535.327,75$ & 36,76 \\
\hline Áreas selladas & $88.985,00$ & 6,11 \\
\hline Franja de sol y arenas & $832.044,00$ & 57,14 \\
\hline Área total & $1.456 .356,75$ & 100,00 \\
\hline
\end{tabular}

FUENTE ELABORACIÓN PROPIA

Por subgrupos, las áreas verdes se distribuyen prácticamente a partes iguales entre aquellas incluidas en la categoría de naturales y reforestadas $\left(267.650,50 \mathrm{~m}^{2}\right)$ y las artificiales $\left(267.677,25 \mathrm{~m}^{2}\right)$. Estos datos demuestran que la vegetación natural y reforestada en la zona costera se ha transformado menos en el interior de las parcelas de los hoteles. En las áreas selladas, predominan las pavimentadas y edificadas. En ocasiones esto conlleva la destrucción de la duna y vegetación costera, un dato preocupante que se explica porque un número importante de hoteles tiene instalaciones levantadas en el interior de esta zona costera. La mayoría fueron edificadas antes del establecimiento del Decreto-Ley N. ${ }^{\circ} 212$, pero hay casos de incumplimiento de lo reglamentado (Tabla 5). 
TABLA 5 Ocupación del suelo en la zona costera

\begin{tabular}{|l|l|c|c|}
\hline \multicolumn{2}{|c|}{ CATEGORÍAS DE USO } & SUPERFICIE $\left(\mathbf{M}^{2}\right)$ & $\begin{array}{c}\text { \% DE LA ZONA COSTERA } \\
\text { OCUPADA }\end{array}$ \\
\hline \multirow{3}{*}{ Áreas verdes } & Naturales y reforestadas & $267.650,50$ & 18,37 \\
\cline { 2 - 4 } & Artificiales & $267.677,25$ & 18,38 \\
\hline \multirow{2}{*}{ Arenas } & Pavimentadas & $832.044,00$ & 57,14 \\
\cline { 2 - 4 } & Edificaciones & $40.617,00$ & 2,79 \\
\cline { 2 - 4 } & Aanchones & $37.971,25$ & 2,61 \\
\cline { 2 - 4 } & Piscinas & $9.816,25$ & 0,67 \\
\hline
\end{tabular}

FUENTE ELABORACIÓN PROPIA

Por último, 33 de los 46 hoteles de la península tienen al menos una parte de sus parcelas ubicadas dentro de la zona costera. Diez hoteles ocupan un sector de la zona costera menor de $10.000 \mathrm{~m}^{2}$; 29 utilizan entre 10.000 y $50.000 \mathrm{~m}^{2}$; y hasta siete superan los $50.000 \mathrm{~m}^{2}$. Las diferencias por periodo de urbanización turística son favorables a aquellos desarrollos más recientes. Esto demuestra que la Ley de Costas de 1997 ha sido efectiva en este sentido. El hotel que más zona costera ocupa es Barceló Marina Palace, con 79.491,60 $\mathrm{m}^{2}$. Los sectores de playa que tienen menos parcelas en esta zona son Punta Hicacos y Chapelín-Los Taínos. En el caso de Punta Hicacos destacan los hoteles Paradisus $\left(22.461,67 \mathrm{~m}^{2}\right)$ y Barceló Marina Palace $\left(79.491,60 \mathrm{~m}^{2}\right)$. En Chapelín-Los Taínos sobresale el Hotel Playa Varadero 1920 $\left(22.119,70 \mathrm{~m}^{2}\right)$. A excepción de Solymar y Palma Real, todos los hoteles de los sectores Internacional y Las Américas presentan esta problemática.

FIgURA 4 | Parcelas hoteleras que incumplen el decreto ley N. ${ }^{\circ} 212$ relativa a la invasión de la zona costera

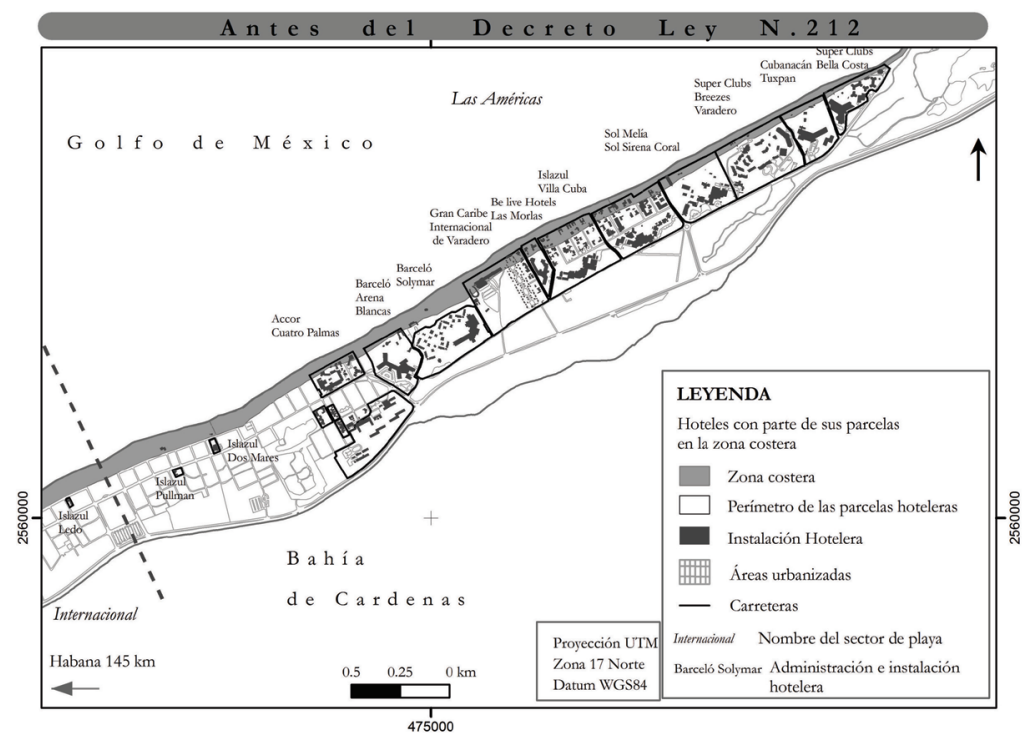

FUENTE ELABORACIÓN PROPIA 
En estos últimos casos, hay que tener en cuenta que en su gran mayoría fueron construidos en las décadas de 1930-1950, durante los ańos de entrada de capital estadounidense a Cuba y cuando apenas existía sensibilidad para la protección del litoral. Por su parte, seis hoteles de Varadero Histórico tienen una parte de sus parcelas en la zona costera. Destacan el hotel Playa Azul, todo él situado en esta zona, y el hotel Herradura, con el $97,90 \%$ de su parcela ubicada también dentro de la zona costera (Figura 4).

\section{Clasificación de los hoteles de acuerdo con la ocupación del suelo}

A modo de síntesis, elaboramos una clasificación de los hoteles en tres categorías en función de la ocupación del suelo en su interior y en la zona costera. Tal y como explicamos de forma detallada en la metodología, se les asignó un valor (en una escala de entre 0 y 3 puntos), teniendo en cuenta los resultados del cálculo de cuatro indicadores. El grupo 1 está formado por aquellos hoteles más respetuosos con la zona costera y que tienen un menor porcentaje de áreas selladas. Se identificaron 14 hoteles, que representan el 26,42\% del total de la península. La mayoría están situados en los sectores de desarrollo más reciente: Chapelín-Los Taínos y Punta Hicacos. Entre estos hoteles destacan: Meliá Las Antillas, Las Salinas, Brisas de Caribe, Iberostar Varadero, Aguas Azules, Turquesa y Palma Real, este último en el sector Varadero Internacional.

El grupo 2 está integrado por hoteles con una ocupación del suelo aceptable. Se contabilizan 13 hoteles $(24,52 \%$ del total). La mayor parte también se encuentran en los sectores Chapelín-Los Taínos y Punta Hicacos y, en menor medida, en Varadero Internacional y Kawama. Destacan los siguientes hoteles: Playa de Oro, Iberostar Taínos, Trip Península, Arenas Doradas, Tuxpan, Breezes Varadero, Playa Caleta, Playa Varadero 1920, Sol Palmera, Kawama, Acuazul-Varazul, Playa Alameda y Barceló Marina Palace. Aunque en este último hotel la proporción de áreas selladas respecto al total es relativamente baja y predominan las áreas verdes en su interior, una parte importante de su parcela está en la zona costera.

El grupo 3, el más numeroso, representa los hoteles con una ocupación del suelo más negativa. Tienen un porcentaje importante de sus parcelas en la zona costera y las áreas selladas superan el 75\% de su superficie. En este grupo hay 26 hoteles, que representan aproximadamente la mitad de todos los de la península. Con la excepción de seis (Paradisus, Sol Coral Sirenas Resort, Blau Varadero, Las Américas, Sandals Royal Hicacos y Bella Costa), los que forman este grupo están entre los más pequeños del polo turístico. En su mayoría son villas y moteles localizados fundamentalmente en los sectores Kawama, Varadero Histórico e Internacional. En este último destaca el hotel Varadero Internacional. En una gran parte, los hoteles que forman este grupo fueron construidos en las décadas de 1950 y 1980. Los hoteles Sandals Royal Hicacos, Blau Varadero y Paradisus son los de más reciente construcción (Tabla 6 y Figura 5). 
TABLA 6 | Agrupamiento de los hoteles según la ocupación del suelo

\begin{tabular}{|l|c|c|}
\hline \multicolumn{1}{|c|}{ CLASIFICACIÓN } & NÚMERO DE HOTELES & \% DEL TOTAL \\
\hline Grupo 1 & 14 & 26,42 \\
\hline Grupo 2 & 13 & 24,53 \\
\hline Grupo 3 & 26 & 49,06 \\
\hline
\end{tabular}

FUENTE ELABORACIÓN PROPIA

FIgURA 5 | Clasificación de los hoteles de acuerdo con la ocupación del suelo

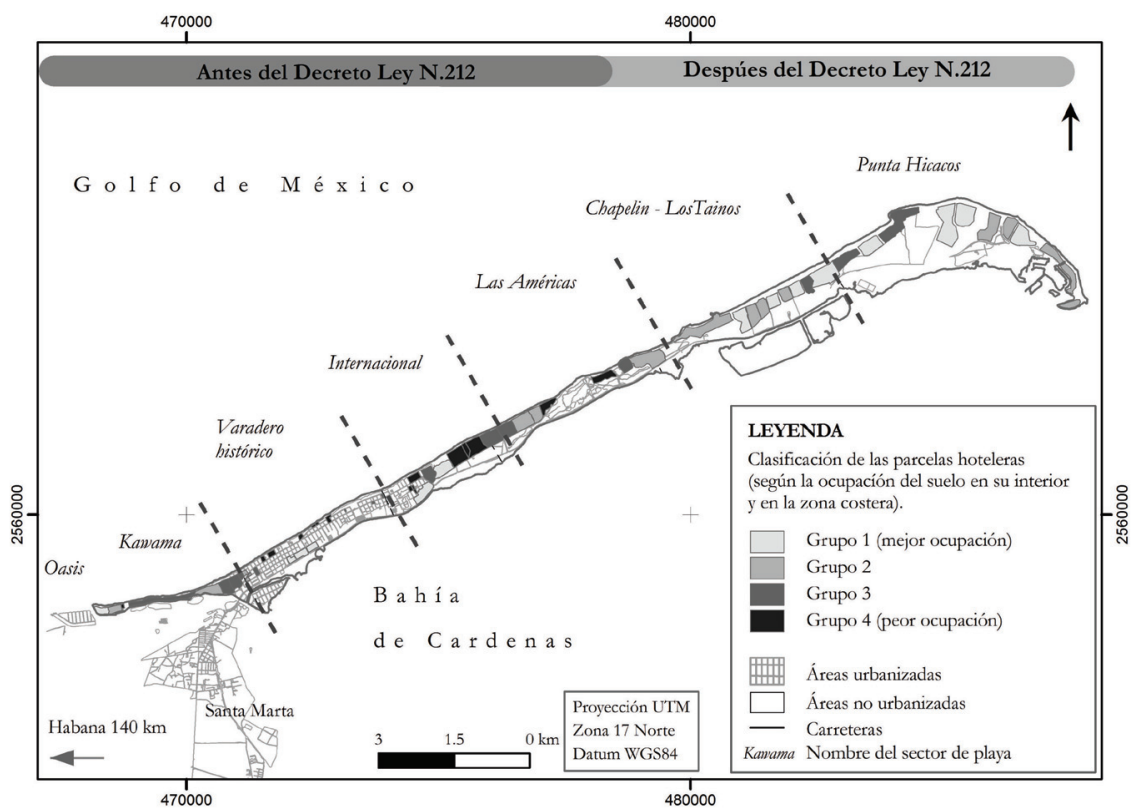

FUENTE ELABORACIÓN PROPIA

En resumen, el nivel de respeto de la zona costera y la distribución de usos en el interior de los resorts se explican por diferentes variables. Una de las más importantes es la fecha de construcción del hotel. Esta es determinante en el modelo de resort proyectado, pero también influye en el grado de afectación de las últimas políticas de control de la urbanización y protección territorial impuestas por el planeamiento y la normativa más recientes, como puede ser el caso de la Ley de Gestión de la Zona Costera de 1997.

\section{Conclusiones}

La península de Hicacos tiene la mayor concentración de plazas hoteleras de Cuba, primer país en número de turistas de las islas del Caribe. Los procesos vinculados a esta industria - consecuencia de una historia que se remonta a la fundación de Hicacos en 1883 y a más de medio siglo de actividad turística intensiva- se concentran en una estrecha franja de unos $23 \mathrm{~km}$ de largo, sin población y asentamientos 
antes de la llegada del turismo. Estos rasgos geográficos favorecieron un modelo de expansión de las instalaciones hoteleras a partir de grandes impulsos turísticos, desde el suroeste (Varadero-Histórico) hacia el norte-noreste, en dirección al extremo noreste de la Punta de Hicacos. En los últimos años, la literatura científica sobre el territorio turístico de Varadero es importante, fundamentalmente en el campo de la geografía del turismo y los estudios ambientales. No obstante, es complicado avanzar en determinadas líneas de investigación, debido a la falta de estadísticas o la ausencia de determinada cartografía, hasta el punto de que muchos de los análisis se fundamentan en hipótesis difíciles de corroborar. En este sentido, este trabajo aporta, por un lado, una información inédita producto de la aplicación de metodologías propias basadas en el diseño y la elaboración de un sig. Esta información podrá ser actualizada y explotada en trabajos posteriores. Es el caso de la clasificación de hoteles por grupos a partir de una metodología fácilmente exportable. Por otro, se demuestran dinámicas de un gran interés espacial, hasta ahora desconocidas o no corroboradas. Y, probablemente lo que es más importante, una línea de investigación y un tipo de análisis sobre los que apenas existen referencias bibliográficas y análisis de casos. Así, la metodología aplicada a escala local (península de Hicacos) es fácilmente exportable a otros territorios, con la importancia que esto tiene tanto a efectos comparativos como para el inicio de nuevas investigaciones en otros destinos turísticos.

El uso de suelo exclusivamente hotelero representa casi el $27 \%$ de la península de Hicacos, alcanzando porcentajes próximos al $40 \%$ en los sectores más recientemente urbanizados. El 97,66\% del suelo de las parcelas hoteleras es artificial. Y en la zona costera delimitada por la vigente ley de costas, el suelo artificial representa el 24,49\%. En consecuencia, la península está ecológicamente muy alterada. La protección y ordenación se ha dejado en manos de interesantes planes territoriales y urbanísticos y del bien valorado Decreto-Ley N. ${ }^{\circ} 212$. El sistema de planeamiento se ha demostrado complejo y completo (González et al. 2014) y la política de costas pudo haber representado un avance importante para la ordenación del litoral. Sin embargo, estos planes y leyes no tienen capacidad suficiente para modificar el modelo económico, ni tan siquiera la mayoría de las estrategias de las grandes multinacionales del sector hotelero, cada vez más interesadas en el gobierno de extensísimas parcelas para el desarrollo del "todo incluido" y determinada oferta complementaria. Dos ejemplos al respecto. Por un lado, tal y como hemos podido demostrar, las instalaciones recientemente construidas son las que ocupan más territorio, las que tienen parcelas más grandes, las que suman mayor superficie de áreas selladas y las que, en la práctica, privatizan el uso de mayores extensiones de suelo de la península. Por otro, los planes territoriales de 1996 y 2001 realizan una interesante apuesta por la protección de territorio de uso público, pero no se aprecian medidas efectivas sobre aquellas parcelas de uso privado (hoteles y resorts), cuando precisamente ellas son el tipo de espacio que más aumentó en la península en las últimas décadas.

En este territorio de poco más de $20 \mathrm{~km}$ de largo, la monofuncionalidad turística es casi absoluta. Sin embargo, el análisis de los datos obtenidos expresa resultados y procesos espacialmente diferentes. Si atendemos a la etapa de urbanización del territorio, los primeros enclaves tienen aspectos positivos relacionados con un desarrollo más o menos próximo a los modelos de ciudad compacta, una más importante 
mezcla de usos y una menor ocupación de suelo. Por su parte, las instalaciones hoteleras más recientes son más respetuosas con el espacio litoral protegido, con aquellas áreas acotadas por el planeamiento y la legislación en un entorno altamente transformado. En los sectores Kawama, Varadero Histórico e Internacional se localiza la mayoría de los 26 hoteles calificados como los de peor ocupación del suelo. En cualquier caso, se ha corroborado que las instalaciones de la primera y fundamentalmente la última etapa turística (1950-1960 y a partir de 1990, respectivamente) son las que tienen mayores superficies de áreas selladas. Por último, este trabajo ha podido demostrar la enorme presión urbanística de los hoteles hacia todo el espacio litoral: 36 de los 46 hoteles estudiados ocupan sectores desiguales de zona costera y el $82,02 \%$ de la primera línea de playa situada detrás del límite de esa zona costera está ocupada igualmente por desarrollos hoteleros.

\section{Referencias bibliográfícas}

Aliagaoglu, A. \& Ugur, A. (2008). Hotels as a Model of Regional Life: The Erzurum Sample. European Planning Studies, 16(10), 1405-1422. doi: 10.1080/09654310802420128.

Antón, S. (1998). La urbanización turística. De la conquista del viaje a la reestructuración de la ciudad turística. Documents D’anàlisi Geogràfica, (32), 17-43. Disponible en http:// www.revistas.unal.edu.co/index.php/rcg/article/view/23072

Arbel, A. \& Pizam, A. (1977). Some determinants of urban hotel location: The tourist's inclinations. Journal of Travel Research, 15(3), 18-22.

Arias, Y. (2005). Ordenamiento ambiental y urbano de un sector de la costa Norte de Varadero, Matanzas. Tesis de Maestría. Facultad de Geografía, Universidad de La Habana, La Habana.

Arias, Y. (2011). Esquema espacial de ordenamiento territorial de Varadero. Matanzas: Oficina de Planeamiento de Varadero.

Ashworth, G. (1989). Accomodation and the historic city. Built Environment, 15(2), 92-100.

Ashworth, G.J. \& Tunbridge, J. E. (1990). The tourist-historic city. Chichester: John Wiley \& Sons. Barragán, J.M. (1998). La ordenación del espacio litoral brasileño: el Plan Nacional de Gestión Costera 1 (PNGC). Anales de la Universidad Complutense, (18), 89-114.

Barragán, J.M. (1994). Ordenación, planificación y gestión del espacio litoral. Barcelona: Oikos-tau.

Barragán, J.M. (Coord.). (2010). Manejo costero integrado y politica pública en Iberoamérica: Un diagnóstico. Necesidad de cambio. Cádiz: Red ibermar (CYTED).

Begin, S. (2000). The geography of a tourist business: Hotel distribution and urban development in Xiamen, China. Tourism Geographies, 2(4), 448-471. doi: 10.1080/146166800750035530

Blázquez, M., Cañada, E. \& Murray, I. (2011). Búnker playa-sol. Conflictos derivados de la construcción de enclaves de capital transnacional turístico español en el Caribe y Centroamérica. Scripta Nova, 368. Disponible en http://www.ub.es/geocrit/sn/sn368.htm 
Cañada, E. (Coord.). (2013). Turismo en Centroamérica. Un diagnóstico para el debate. Managua: Enlace.

Cazes, G. (1994). Le tourisme international dans les relations nord-sud. Perspectives territoriales et géopolitiques. Teoros, 13(2), 8-11.

Consejo de Estado de la República de Cuba. (2000). Decreto-Ley N. ${ }^{\circ} 212$ Gestión de la zona costera. La Habana: Gaceta Oficial de la República.

Chang, T.C. \& Huang, S. (2004). Urban tourism: Between the global and the local. En A.A. Lew, C.M. Hall \& A.M. Williams, A companion to tourism (pp. 223-234). Oxford: Blackwell.

Clarke, C.G. (1974). Urbanization in the Caribbean. Geography 59(3), 223-232.

Consejo de Estado de la República de Cuba. (2000). Decreto-Ley N. ${ }^{\circ} 212$. Gestión de la zona costera. La Habana: Gaceta Oficial de la República.

Egan, D.J. \& Nield, K. (2000). Towards a theory of intraurban hotel location. Urban Studies, 37(3), 611-621. doi: 10.1080/0042098002140

Dadon, J.R. (2010). Manejo costero en la República de Argentina. En J.M. Barragán (Coord.), Manejo costero integrado y politica pública en Iberoamérica: Un diagnóstico. Necesidad de cambio (pp. 235-260). Cádiz: Red IBERMAR (CYTED).

De Bres, K. (1994). Cowtowns or cathedral precincts? Two models for contemporary urban tourism. Area, 26(1), 57-67.

Dokmeci, V. \& Balta, N. (1999). The evolution and distribution of hotels in Istanbul. European Planning Studies, 7(1), 99-109. doi: 10.1080/09654319908720504

García, R. (1987). Geografía fisica del océano. La Habana: Universidad de La Habana.

González, J.M. (Ed.). (2012). La nueva fiebre del oro. Las otras ciudades del turismo en el Caribe (Varadero, Bávaro-Punta Cana). Palma: Universitat de les Illes Balears.

González, J.M., Salinas, E., Navarro, E., Artigues, A.A., Remond, R., Yrigoy, I, Echarri, M. \& Arias, Y. (2014). The city of Varadero (Cuba) and the urban construction of a tourist enclave. Urban Affairs Review, 50(2), 206-243. doi: 10.1177/1078087413485218

Harvey, D. (2004) El nuevo imperialismo. Madrid: Akal.

Hofmayer, A. (1986). Some geographical aspects of tourism in Vienna. En F. Vetter (Ed.), Big City Tourism (pp. 200-213). Berlín: Reimer Verlag.

Kerimoglu, E. \& Ciraci, H. (2006). The evolution of relation between spatial distribution of hotels and business services with respect to spatial development of Istanbul. Paper presented at the International Conference on Regional and Urban Modeling, Brussels, 1-2 June.

López, F. \& Vera, J.F. (2001). Espacios y destinos turísticos. En A. Gil \& J. Gómez (Coord.), Geografia de España (pp. 545-571). Barcelona: Ariel.

Ministerio de Turismo (mintur). (2011). Planificación del desarrollo turístico en Cuba. La Habana (inédito).

Morales, A., Silva, M. \& González, C. (2010). La gestión integrada de la zona costera en Costa Rica: experiencias y perspectivas. En J.M. Barragán (Coord.), Manejo costero integrado y política pública en Iberoamérica: Un diagnóstico. Necesidad de cambio (pp. 41-70). Cádiz: Red IBERMAR (CYTED). 
Navarro-Jurado, E., Thiel-Ellul, D. \& Romero-Padilla, Y. (2015). Periferias del placer: Cuando turismo se convierte en desarrollismo inmobiliario-turístico. Boletín de la Asociación de Geógrafos Españoles, (67), 275-302. Disponible en http://www.boletinage.com/ articulos/67/13_periferias.pdf

Oppermann, M., Din, K. \& Amri, S. (1996). Urban hotel location and evolution in a developing country. The case of Kuala Lumpur, Malaysia. Tourism Recreation Research, 21(1), 55-63. doi: 10.1080/02508281.1996.11014763

Page, S. \& Sinclair, T. (1989). Tourism and accommodation in London: Alternative policies and the docklands experience. Built Environment, 15(2), 125-137.

Pearce, D. (1987). Motel location and choice in Christchurch, New Zealand. Geographers, 43(1), 10-17.

Prieto, F. \& Ruiz, J.B. (2013). Costas inteligentes. Madrid: Greenpeace. doi: 10.1111/j.17457939.1987.tb01203.x

Rey, O., Cruz, T., López, A. de la C., Whittle, D. \& Kanepa, C. (2008). Manual de legislación ambiental para la gestión de la zona costera de Cuba. La Habana: CITMa. Disponible en http://www.edf.org/sites/default/files/9619_EDF_CubaHandbook_Spanish.pdf

Ritter, W. (1986). Hotel location in big cities. En F. Vetter (Ed.), Big City Tourism (pp. 355364). Berlín: Reimer Verlag

Salinas, E. \& Mundet, Ll. (2000). El turismo en Cuba. Un análisis geográfico. Geographicalia (no seriada), 53-66. Disponible en http://dialnet.unirioja.es/servlet/articulo?codigo=59915

Seco, R. (2004). Geomorfología. La Habana: Félix Varela.

Shaw, B. \& Williams, S. (1994). Critical issues in tourism: A geographical perspective. Oxford: Blackwell.

Shoval, N. (2006). The geography of hotels in cities: An empirical validation of forgotten model. Tourism Geographies, 8(1), 56-75.

Shoval, N. \& Cohen-Hattab, K. (2001). Urban hotel development patterns in the face of political shifts. Annals of Tourism Research, 28(4), 908-925.

Timothy, D. \& Wall, G. (1995). Tourist accommodation in an Asian historic city. The Journal of Tourism Studies, 6(2), 63-73.

Urtasun, A. \& Gutiérrez, I. (2006). Hotel locations in tourism cities. Madrid, 1936-1998. Annals of Tourism Research, 33(2), 382-402. http://dx.doi.org/10.1016/j.annals.2005.12.008

Violier, Ph. [en collaboration avec A. Rey]. (2000). Points de vue et lieux touristiques du monde. Mappemonde, 57(1), 7-11. Disponible en http://www.mgm.fr/PUB/Mappemonde/ M100/Violier.pdf

Wall, G., Dudycha, D. \& Hutchinson, J. (1985). Point pattern analyses of accommodation in Toronto. Annals of Tourism Research, 12(4), 603-618.

Weaver, D. (1993). Model of urban tourism for small Caribbean islands. Geographical Review, 83(2), 134-140. doi: 10.2307/215251

Yokeno, N. (1968). La localisation de l'industrie touristique: Application de l'analyse de Thunen-Weber. Cahiers du CHE, série C, 9.

Zoido, F., De la Vega, S., Piñeiro. Á., Morales, G., Mas, R., Lois, R.C. \& González, J.M. (2013). Diccionario de urbanismo, geografía urbana y ordenación del territorio. Madrid: Cátedra. 
